\title{
Exploring Photovoltaic Feasibility of Pentaaryl [60]Fullerene in Bulk Heterojunction Architecture
}

\author{
Tsubasa Mikie, Akinori Saeki", Naohiko Ikuma, Ken Kokubo, and Shu Seki* \\ Department of Applied Chemistry, Graduate School of Engineering, \\ Osaka University, Osaka 565-0871, Japan.
}

\begin{abstract}
The photochemical process of pentaaryl [60]fullerenes $\left(\mathrm{PAC}_{60}\right)$ has been investigated by fluorescence and transient absorption spectroscopies, aiming at their use in bulk heterojunction organic photovoltaic (OPV). Fluorescence quenching was observed by adding $\mathrm{C}_{60}$ into $\mathrm{PAC}_{60}$, where the intensity was decreased in an exponential manner. The photo-generated radical cation of $\mathrm{PAC}_{60}$ was identified at $925 \mathrm{~nm}$ in the presence of electron acceptor. Motivated from the observed shallow molecular orbital levels of $\mathrm{PAC}_{60}$, we performed conceptual study of all-fullerene $\mathrm{OPV}$, where $\mathrm{PAC}_{60}$ and $[6,6]$-phenyl- $\mathrm{C}_{61}$-butyric acid methyl ester (PCBM) were presumably used as a p-type and n-type semiconductor, respectively. The power conversion efficiency was $0.007 \%$, much smaller than $0.05 \%$ found for the conventional combination of P3HT (p-type) and $\mathrm{PAC}_{60}$ (n-type). The mechanism is discussed on the basis of photoconductive and spectroscopic results.
\end{abstract}

keywords: organic solar cell, transient absorption spectroscopy, time-resolved microwave conductivity

\section{Introduction}

Organic photovoltaic cells (OPV) have attracted a great deal of attentions due to their low-cost and wide-area fabrication on a light-weight flexible substrate. ${ }^{1,2)}$ P-type conjugated polymers and n-type fullerenes are the key materials in this regard. ${ }^{3,4)}$ The nano-scale $\mathrm{p} / \mathrm{n}$ bicontinuous network, termed bulk heterojunction, leads to the dramatic improvement of charge separation efficiency. Currently the power conversion efficiency (PCE) of single layer OPV exceeds $11 \%$, approaching the criteria of commercialization. ${ }^{5,6)}$

As a counterpart of the conventional framework of p-type polymer and n-type fullerene, all-polymer OPV (p-type and n-type polymers) ${ }^{7-9)}$ and non-fullerene OPV (p-type polymer and n-type molecule) $)^{10,11)}$ have been investigated to explore the potential diversity of organic semiconductors. The PCEs are, however, still much lower than the polymer-fullerene OPV. The reason is likely linked to the delocalization of hole along the backbone, ${ }^{12)}$ crystallite of fullerene, ${ }^{13)}$ energy gradient in the mixed phase of polymer and fullerene, ${ }^{14)}$ and entropy of isotropic fullerenes domains, ${ }^{15}$ ) all of which facilitate efficient charge separation in polymer-fullerene
OPV to escape from the strong Coulomb potential.

Interestingly, p-type nature of fullerene derivatives has been reported in the last decade. Anthopoulos et al. have demonstrated the ambipolar carrier transport in field-effect transistor of PCBM. ${ }^{16,17)}$ Nelson et al. have found a pronounced hole mobility in poly(paraphenylenevinylene):MDMO-PPV and PCBM blend films greater than the pristine polymer film, indicative of the hole transport in PCBM aggregates, ${ }^{18)}$ which was later supported by ultrafast spectroscopy. ${ }^{19)}$ Recently, unconventional use of $\mathrm{C}_{60}$ or PCBM as a p-type semiconductor in OPV has been reported by some groups, where fluorinated-phthalocyanine $\left(\mathrm{F}_{16}-\mathrm{ZnPc}\right)^{20,21)}$ or oligo-thiophene end-capped by strong electron withdrawing unit ${ }^{22)}$ act as a n-type material. Furthermore, controlling the Fermi energy of $\mathrm{C}_{60}$ was realized by precise doping of $\mathrm{MoO}_{3}$ or $\mathrm{Ca}$ into the ultrapure $\mathrm{C}_{60}$ film. ${ }^{23,24)}$ Synthetic chemistry also provides an attractive route toward precise tuning of the energy level by functionalizing the fullerene cage. ${ }^{25-27)}$

Herein, we focused on the multi-addition of fullerene which is known as a versatile approach to raise the lowest unoccupied molecular orbital (LUMO) level. To this end, pentaaryl 
[60]fullerenes $\left(\mathrm{PAC}_{60}\right)$ developed by Nakamura et $a l^{28-30)}$ are appropriate motifs, due to their facile synthetic procedure with a good yield. We have also investigated photochemical properties of $\mathrm{PAC}_{60}$ in solution by transient absorption spectroscopy (TAS) and photoelectric conversion in film state by time-resolved microwave conductivity (TRMC). Finally we examined the OPV performance of PCBM:PAC $_{60}$ and P3HT:PAC 60 systems.

\section{Experimental}

$\mathrm{PAC}_{60} \mathrm{~S}(\mathbf{1} \mathbf{a}-\mathbf{d})$ were synthesized in the same way with Nakamura et $a l^{28-30)}$ The chemical structures are drawn in Figure 1. They were identified by ${ }^{1} \mathrm{H}-\mathrm{NMR},{ }^{13} \mathrm{C}-\mathrm{NMR}$, and MALDI-TOF-MASS. The highest occupied molecular orbital (HOMO) levels were measured by photoelectron yield spectroscopy (PYS). The LUMO levels in the film state were obtained by adding the optical bandgap (absorption edge) to the HOMO levels. Fluorescence quenching was measured in $o$-dichlorobenzene $(o$-DCB) solutions by a fluorescence spectrometer $\left(\lambda_{\mathrm{ex}}=\right.$ $300 \mathrm{~nm}$ ). TAS experiments were performed by a streak camera or a Si-PIN photodetector upon $355 \mathrm{~nm}$ excitation from a nanosecond $\mathrm{Nd}$ :YAG laser. The details of TRMC measurements (9.1 $\left.\mathrm{GHz}, \quad \lambda_{\mathrm{ex}}=355 \mathrm{~nm}\right)$ have been reported previously. $^{31)}$

OPV devices were fabricated according to our previous report. $^{32)}$ The device configuration is ITO/PEDOT:PSS/Active layer/Ca(20nm)/Al(100 $\mathrm{m}) . o$-DCB without any additives was used as a solvent. Current-voltage $(J-V)$ curves were measured using a source-measure unit under AM $1.5 \mathrm{G}$ solar illumination at $100 \mathrm{mWcm}^{-2}$ (1 sun) using a $300 \mathrm{~W}$ solar simulator.

\section{Results and discussion}

The energy diagram of $\mathrm{PAC}_{60} \mathrm{~S}$ along with $\mathrm{C}_{60}$ and PCBM is shown in Figure 1. The penta-phenyl adduct (1a) revealed a significant raise of LUMO by $0.6 \mathrm{eV}$ compared with the bare

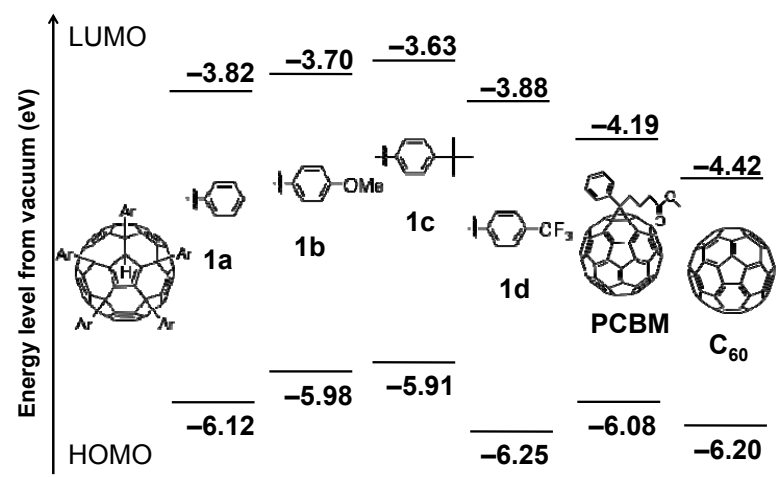

Figure 1. Energy diagram of fullerene derivatives in film states determined from PYS and optical bandgap.
$\mathrm{C}_{60}$. By substituting proton for electron-donating methoxy (1b) and $t$-butyl (1c) at the para-position of the phenyls, the LUMOs are further elevated from $-3.82 \mathrm{eV}(\mathbf{1 a})$ to $-3.70 \mathrm{eV}(\mathbf{1 b})$ and $-3.63 \mathrm{eV}$ (1c). Simultaneously, the HOMOs of these three $\mathrm{PAC}_{60} \mathrm{~S}$ were lowered with keeping the identical bandgap energy (ca. $2.3 \mathrm{eV}$ ). Inversely, the electron-withdrawing trifluoromethyl substitution deepened the LUMO level to $-3.88 \mathrm{eV}$ (1d). Notably, the HOMO $(-6.25 \mathrm{eV})$ was deeper than those of PCBM and $\mathrm{C}_{60}$. These substitutions allowed the control of the energy level by inductive effect of substituents.

In order to examine the electronic interaction between $\mathrm{PAC}_{60}$ and fullerene, fluorescence quenching was measured in $o$-DCB solution. The $\mathrm{C}_{60}$ was selected as the counterpart, because it has the lowest-lying LUMO. The most basic $\mathrm{PAC}_{60}$ structure, 1a, exhibited an intense orange fluorescence at $595 \mathrm{~nm}$ (Figure 2a). Upon addition of $\mathrm{C}_{60}$, the fluorescence was progressively quenched in the exponential manner (Figure 2b). $\mathrm{C}_{60}$ has a very weak fluorescence at ca. $700 \mathrm{~nm}^{32}$ ) as a result of symmetrically forbidden transition from the excited singlet state to ground state. ${ }^{34)}$ The observed nonlinear dependence of the intensity on $\mathrm{C}_{60}$ content suggests that the electron or energy transfer is involved in the fluorescence quenching. More distinguished quenching was observed in the blend film, where only the presence of $0.11 \mathrm{wt}^{\%} \mathrm{C}_{60}$ quenched about $90 \%$ of fluorescence from 1a, due to the efficient exciton migration in the film (Figure $2 b$ ).

To gain access to spectroscopic information of the short-lived species of 1a, we carried out TAS in $\mathrm{N}_{2}$-purged $o$-DCB solution. Figure $3 \mathrm{a}$ shows the TAS spectra at the pulse end observed for the single component of $\mathbf{1 a}$ or $\mathrm{C}_{60}$. The characteristic spectrum of $\mathrm{C}_{60}$ solution centered at $740 \mathrm{~nm}$ is readily ascribed to the triplet excited state, in accordance with the literatures. ${ }^{35,36)}$ Similarly, we can safely attribute the 1a spectrum
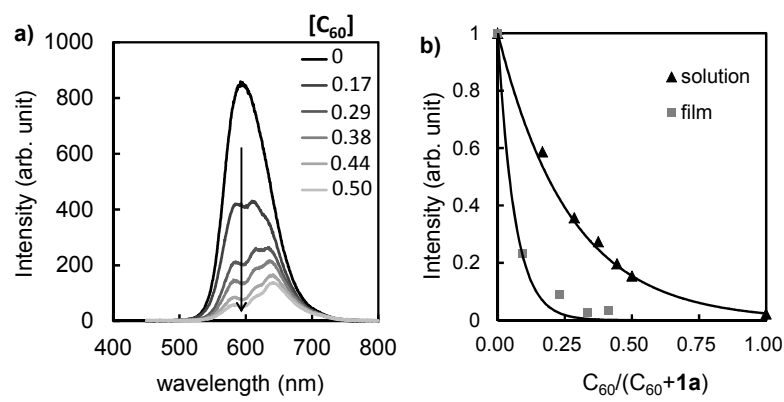

Figure 2. (a) Fluorescence spectra of $1 \mathrm{a}(0.25 \mathrm{wt} \%$ in $o$-DCB) upon addition of $\mathrm{C}_{60} .\left[\mathrm{C}_{60}\right]$ is the weight fraction of $\mathrm{C}_{60}$ given by $\mathrm{C}_{60} /\left(\mathrm{C}_{60}+\mathbf{1 a}\right) . \lambda_{\text {ex }}=300 \mathrm{~nm}$. (b) Dependence of intensity integrated over the photon energy on $\left[\mathrm{C}_{60}\right]$ in solution (triangles) and film (square). 
centered at $660 \mathrm{~nm}$ to its triplet excited state $\left({ }^{3} \mathbf{a}^{*}\right)$. The time profiles at their maxima followed a single exponential decay with the lifetimes of 9.3 and $4.7 \mu \mathrm{s}$ for ${ }^{3} \mathbf{1 a}^{*}$ and ${ }^{3} \mathrm{C}_{60}{ }^{*}$, respectively (Figure 3b).

In sharp contrast, the TAS spectrum of 1a was drastically changed to the broad feature with the maximum at $925 \mathrm{~nm}$ in the presence of excess amount of strong electron acceptor: tetracyanoethylene (TCNE, 1:20 in wt fraction) (Figure 3c). Ohkita et al. has investigated the photo-induced electron transfer from TCNE to PCBM and assigned the absorption peak at 890 $\mathrm{nm}$ to the PCBM radical cation. ${ }^{37)}$ Accordingly, 1 a radical cation is the intermediate that gives the absorption in 1a:TCNE solution.

Having all that in mind, the TAS experiment was conducted for the $o$-DCB solution of $\mathbf{1 a}$ and $\mathrm{C}_{60}$ mixture $(1: 1$ in $\mathrm{w} / \mathrm{w} \%)$, which exhibited approximately $80 \%$ quenching of fluorescence from 1a (Figure 2). The TAS spectra in Figure 3d, however, indicate a single dominant peak at ca. $750 \mathrm{~nm}$ arisen from $\mathrm{C}_{60}$ triplet excited state. Neither radical cation nor triplet of $1 \mathbf{a}$ appeared at all even after $10 \mu$ s delay. Therefore, we can conclude that energy transfer from $\mathbf{1 a}$ to $\mathrm{C}_{60}$, eventually giving rise to the triplet excited state of the latter, is the primary process in the fluorescence quenching rather than electron transfer.

Photocarrier generation processes were also traced in the blend films of $\mathrm{PAC}_{60}$ with $\mathrm{P} 3 \mathrm{HT}$ or
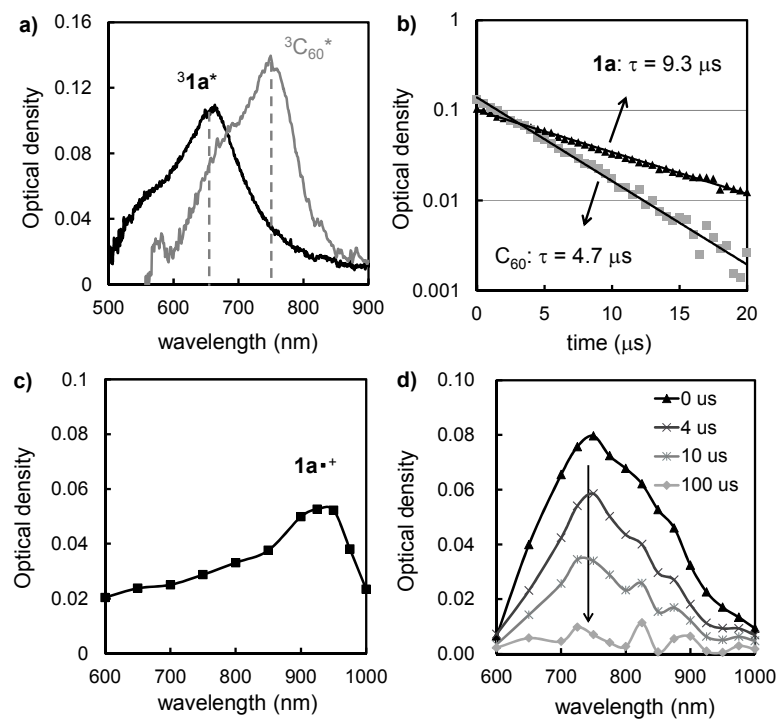

Figure 3. (a) End-of-pulse transient absorption spectra of triplet excited states of $\mathbf{1 a}\left({ }^{3} \mathbf{1 a}^{*}\right.$, black line) and $\mathrm{C}_{60}$ $\left({ }^{3} \mathrm{C}_{60}{ }^{*}\right.$, gray line) observed in $\mathrm{N}_{2}$-bubbled $o$-DCB solutions excited at $355 \mathrm{~nm}$. (b) Semi-logarithmic decay plots of ${ }^{3} \mathbf{1 a}^{*}$ (black triangles) and ${ }^{3} \mathrm{C}_{60}{ }^{*}$ (gray squares) at their maxima. (c) End-of-pulse transient absorption spectrum of $o$-DCB solution of $0.5 \mathrm{wt} \%$ 1a with $10 \mathrm{wt} \%$ TCNE. (d) Time evolution of transient absorption spectra in $o$-DCB solution of $1 \mathrm{a}: \mathrm{C}_{60}=1: 1(\mathrm{w} / \mathrm{w} \%)$.
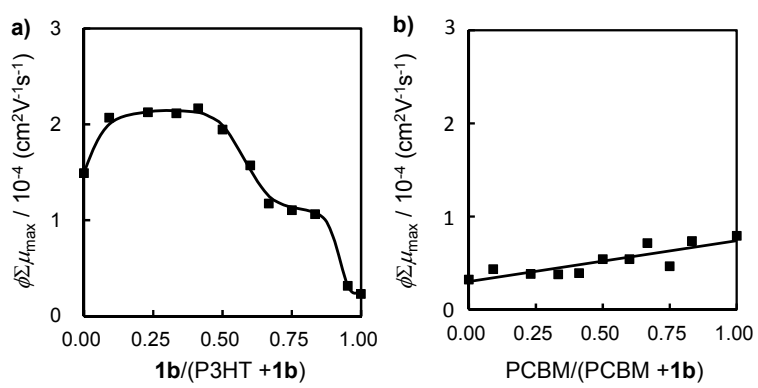

Figure 4. TRMC transient maxima $\left(\phi \Sigma \mu_{\max }\right)$ of (a) P3HT: 1b and (b) 1b:PCBM blend films $\left(\lambda_{\mathrm{ex}}=355 \mathrm{~nm}\right)$.

PCBM by TRMC. Hereafter $\mathbf{1 b}$ was used instead of 1a, because of its superior film quality. The transient maxima, $\phi \Sigma \mu_{\max } \quad(\phi$ : charge carrier generation efficiency, $\Sigma \mu$ : the sum of hole and electron mobilities), display a marginal increase for the mixture of P3HT and $\mathbf{1 b}$ (Figure 4a), but the largest $\phi \Sigma \mu_{\max }$ is two orders of magnitude smaller than P3HT:PCBM. ${ }^{32)}$ 1b:PCBM presented a further suppressed and straight dependence of $\phi \Sigma \mu_{\max }$, indicating the absence of charge separation through electron transfer from PCBM to 1b. This TRMC result is consistent with the conclusion of inefficient charge separation upon excitation deduced from the fluorescence quenching and TAS experiments.

Finally, we evaluated OPV of P3HT: 1b and 1b:PCBM (Figure 5). After the optimization of blend ratio and processes, the maximized PCEs were $0.049 \%$ for P3HT:1b $=1: 1 \quad\left(J_{s c}=0.17 \mathrm{~mA}\right.$ $\left.\mathrm{cm}^{-2}, V_{o c}=0.62 \mathrm{~V}, \mathrm{FF}=0.47\right)$ and $0.0071 \%$ for 1b:PCBM $\left(J_{s c}=0.044 \mathrm{~mA} \mathrm{~cm}{ }^{-2}, V_{o c}=0.28 \mathrm{~V}, \mathrm{FF}\right.$ $=0.28)$. This fairly poor performance of all-fullerene OPV suffers strongly from the insufficient charge separation revealed by TAS and TRMC. Narrowing the bandgap of p-type fullerene to prevent the energy transfer is necessary for further improvement, with preserving the shallow LUMO levels.

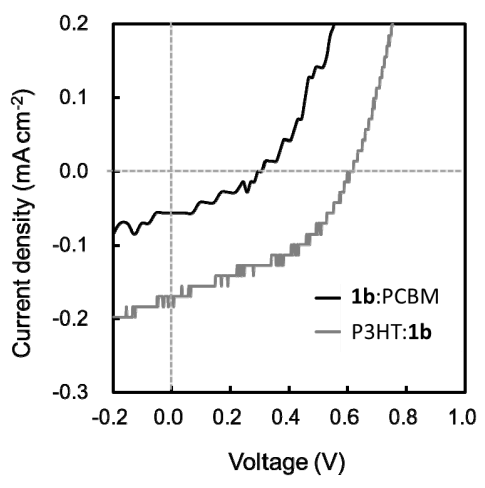

Figure 5. $J-V$ curves of P3HT:1b (1:3 w/w, gray line) and 1b:PCBM $(1: 1 \mathrm{w} / \mathrm{w}$, black line) processed from $o$-DCB without thermal annealing under AM 1.5G (100 $\left.\mathrm{mWcm}^{-2}\right)$. 


\section{Conclusion}

We demonstrated that HOMO and LUMO of $\mathrm{PAC}_{60} \mathrm{~S}$ are significantly raised in comparison with PCBM and $\mathrm{C}_{60}$ by rational tailoring of inductive effect at the para position. The radical cation and triplet excited state of 1a has been characterized by TAS, the absorption maxima of which are 925 and $660 \mathrm{~nm}$, respectively. The fluorescence quenching of $\mathrm{PAC}_{60}$ by addition of $\mathrm{C}_{60}$ was ascribed to the energy transfer rather than electron transfer, as unveiled by TAS and TRMC. The optimized PCEs of $0.05 \%$ were found for polymer-fullerene OPV and $0.007 \%$ for allfullerene OPV.

\section{Acknowledgements}

This work was supported by JSPS Funding Program for NEXT Program, the PRESTO program of JST, and KAKENHI from MEXT, Japan. T. Mikie thanks the financial support of JSPS scholarship.

\section{References}

1. A. C. Arias, J. D. Mackenzie, I. McCulloch, J. Rivnary, A. Salleo, Chem. Rev. 110 (2010) 3.

2. G. Li, R. Zhu, Y. Yang, Nature Photo. 6 (2012) 153.

3. Y. Kim, S. Cook, S. M. Tuladhar, S. A. Choulis, J. Nelson, J. R. Durrant, D. C. Bradley, M. Giles, I. McCulloch, C. S. Ha, M. Ree, Nature. Mater. 5 (2006) 107.

4. G. Demmler, M. C. Scharber, C. J. Brabec, Adv. Mater, 21 (2009) 1323.

5. R. F. Service, Science, 332 (2011) 293.

6. M. A. Green, K. Emery, Y. Hishikawa, W. Warta, E. D. Dunlop, Progress in Photovoltaics, 22, (2014) 1.

7. C. R. McNeill, A. Abrusci, J. Zaumseil, R. Wilson, M. J. McKiernan, J. H. Burroughes, J. J. M. Halls, N. C. Greenham, R. H. Friend, Appl. Phys. Lett. 90 (2007) 193506.

8. D. Mori, H. Benten, H. Ohkita, S. Ito, K. Miyake, ACS Appl. Mater. Interfaces 4 (2012) 3325.

9. M. Ide, Y. Koizumi, A. Saeki, S. Seki, J. Photopolym. Sci. Tech. 26 (2013) 217.

10. H. Li, F. S. Kim, G. Ren, E. C. Hollenbeck, S. Subramaniyan, S. A. Jenekhe, Angew. Chem. Int. Ed., 52 (2013) 5513.

11. R. Shivanna, S. Shoaee, S. Dimitrov, S. K. Kandappa, S. Rajaram, J. R. Durrant, K. S. Narayan, Energy Environ. Sci.7 (2014) 435.

12. C. Deibel, T. Strobel, V. Dyakonov, Phys. Rev. Lett. 103 (2009) 036402.

13. B. M. Savoie, A. Rao, A. A. Bakulin, S. Gélinas, B. Movaghar, R. H. Friend, T. J. Marks, M. A. Ratner, J. Am. Chem. Soc. 136 (2014) 2876.
14. T. M. Burke, M. D. McGehee, Adv. Mater. 26 (2014) 1923.

15. B. A. Gregg, J. Phys. Chem. Lett. 2 (2011) 3013.

16. T. D. Anthopoulos, C. Tanase, S. Setayesh, E. J. Meijer, J. C. Hummelen, P. W. M. Blom, D. M. D. Leeuw, Adv. Mater. 16 (2004) 2174.

17. T. D, Anthopoulos, D. M. D. Leeuw, E. Cantatore, S. Setayesh, E. J. Meijer, Appl. Phys. Lett. 85, (2004) 4205.

18. S. M. Tuladhar, D. Poplavskyy, S. A. Choulis, J. R. Durrant, D. D. C. Bradley, J. Nelson, $A d v$. Funct. Mater. 15 (2005) 1171.

19. S. Yamamoto, H. Ohkita, H. Benten, S. Ito, Adv. Funct. Mater. 22 (2012) 3075.

20. Q. L. Song, H. B. Y, Y. Gan, C. Gong, C. M. Li, J. Am. Chem. Soc. 132 (2010) 4554.

21. J. L. Yang, P. Sullivan, S. Schumann, I. Hancox, T. S. Jones, Appl. Phys. Lett. 100 (2012) 023307.

22. Y. Ie, M. Karakawa, S. Jinnai, H. Yoshida, A. Saeki, S. Seki, S. Yamamoto, H. Ohkita, Y. Aso, Chem. Commun. 50 (2014) 4123.

23. M. Kubo, K. Iketani, T. Kaji, M. Hiramoto, Appl. Phys. Lett. 98 (2011) 073311.

24. M. Kubo, T. Kaji, M. Hiramoto, AIP. Advances. 1 (2011) 032177.

25. F. B. Kooistra, J. Knol, F. Kastenberg, L. M. Popescu, W. J. H. Verhees, J. M. Kroon, J. C. Hummelen, Org. Lett. 9 (2007) 551.

26. K. H. Kim, H. Kang, S. Y. Nam, J. Jung, P. S. Kim, C. H. Cho, C. Lee, S. C. Yoon, B. J. Kim, Chem. Mater. 23 (2011) 5090.

27. Y. Matsuo, J. Kawai, H. Inada, T. Nakagawa, H. Ota, S. Otsubo, E. Nakamura, Adv. Mater. 25 (2013) 6266.

28. M. Sawamura, H. Iikura, E. Nakamura, J. Am. Chem. Soc. 118 (1996) 12850.

29. M. Sawamura, H. Iikura, T. Ohama, U. E. Hackler, E. Nakamura, J. Organomet. Chem. 599 (2000) 32.

30. Y. Matsuo, E. Nakamura, Chem. Rev. 108 (2008) 3016.

31. A. Saeki, Y. Koizumi, T. Aida, S. Seki, Acc. Chem. Res. 45 (2012) 1193.

32. A. Saeki, S. M. Tsuji, S. Seki, Adv. Energy Mater. 1 (2011) 661.

33. Y. Zhao, Y. Fang, J. Phys. Chem. B 108 (2004) 13586.

34. F. Negri, G. Orlandi, F. Zerbetto, J. Chem. Phys. 97 (1992) 6496.

35. N. M, Dimitrijević, P. V. Kamat, J. Phys. Chem. 96 (1992) 4811.

36. A. Acharya, S. Seki, Y. Koizumi, A. Saeki, S. Tagawa, J. Phys. Chem. B 109 (2005) 20174.

37. S. Yamamoto, J. Guo, H. Ohkita, S. Ito, $A d v$. Funct. Mater. 15 (2008) 2555. 